Wenwen Cao, Fangdi Cong*, Jie Kang, Shulin Zhang, Xin Li, Xinxin Wang, Ping Li and Jinze $\mathrm{Yu}$

\title{
A simple room temperature-static bioreactor for effective synthesis of hexyl acetate
}

https://doi.org/10.1515/gps-2020-0006

Received June 01, 2019; accepted September 04, 2019.

Abstract: For green synthesis in organic phases, the catalysis of lipases needs to be further improved. Here a strategy is to simulate the activation of lipases at water/oil interface by immobilizing lipase on an available carrier material, which can replace the water at the interface to stabilize enzyme against denaturation from organic phase. The carrier is selected as cotton fiber on which Pseudomonas cepacia lipase is immobilized by physical adsorption in a column glass bottle to form a simple bioreactor together with the bottle. In synthesis of fragrance ester hexyl acetate via transesterification of hexanol with vinyl acetate, the bioreactor exhibits a 3-fold increase in the ability to transform substrate, relative to native lipase in terms of the initial period of reaction at $37^{\circ} \mathrm{C}$ and $160 \mathrm{rpm}$. And also the bioreactor is very stable in catalysis for that it has an extra long half life $t_{1 / 2}=636 \mathrm{~h}$, calculated from the decrease degree of molar conversions in six times of 6-hour transesterifications. More interestingly, the bioreactor behaves excellent activity at room temperature and in a static state, and can transform nearly 100\% hexanol after $48 \mathrm{~h}$. All these indicate that the bioreactor has great potential for industrial application.

Keywords: bioreactor; catalysis; lipase; nonaqueous phase; hexyl acetate

\footnotetext{
* Corresponding author: Fangdi Cong, Department of Biopharmaceutics, College of Basic Sciences, Tianjin Agricultural University, Tianjin 300384, China; Tianjin Key Lab of Aqua-ecology and Aquaculture, Fisheries College, Tianjin Agricultural University, Tianjin 300384, China. Tel/fax: +86 02223781295 ,

email: congfangdi@163.com

Wenwen Cao, Jie Kang and Ping Li, Department of Biopharmaceutics, College of Basic Sciences, Tianjin Agricultural University, Tianjin 300384, China

Shulin Zhang, Xin Li and Xinxin Wang, Tianjin Key Lab of Aquaecology and Aquaculture, Fisheries College, Tianjin Agricultural University, Tianjin 300384, China

Ping Li and Jinze Yu, Key Laboratory of Storage of Agricultural Products, Ministry of Agriculture and Rural Affairs, National Engineering Technology Research Center for Preservation of Agricultural Products, Tianjin 300384, China
}

\section{Introduction}

Green synthetic pathways, especially those catalyzed by enzymes, are greatly desirable because they are not only environmentally friendly but also highly productive [1]. For example lipases, many of them exhibit activity in nearly anhydrous reaction systems and therefore behave extensive applications in enzyme chemical industries [2]. These enzymes can be used to synthesize valuable esters such as sitostanol esters [3], cinnamyl esters [4] and flavonoid esters [5], etc. However, they usually lacked necessary activity and solvent-tolerated stability in organic phases, which significantly impeded the practical application of them as biocatalysts in green chemical process [6]. Thus, a lot of effort has been carried out to enhance the nonaqueous catalysis of them, which mainly included two aspects, one was to find novel lipases with stable conformations by genetic and protein engineering $[7,8]$, the other was to optimize them by external factors summarized as water activity [9], solvents [10] and enzyme immobilization [11]. At present, many lipases have been developed and commercialized, and it is necessary to study the effects of these external factors on enzyme catalysis $[2,5]$.

Water as a molecular lubricant can directly act with polar groups of enzyme proteins and maintain them with fine flexibility demanded for catalysis, but too little water is easily drawn into organic phases and too much water will reverse ester synthesis to hydrolysis [12]. Organic solvents commonly benefit ester synthesis but have main responsibility for denaturation of enzyme proteins. And the disadvantageous changes were ever lessened as far as possible by selecting solvents in terms of polarity [13], structure [6] and composition [14], or using ionic liquids [15]. Often the preferred solvent systems brought inconvenience in separation and purity of products [13]. Comparatively, the immobilization of lipases is an option to effectively improve catalysis of them in organic phases for that water activity no longer needs to worry and solidliquid separation is also facile [3,4].

Actually, almost all the work on preparation of immobilized lipases is to stabilize enzyme conformation 
and decrease diffusion restriction of enzymes as far as possible, and the theoretical basis is the interfacial activation of lipases at the water/oil (organic phase) interface [9-11]. The typical lipase generally has a section of mobile amphiphilic $\alpha$-helix, called 'lid' structure, over the active site. At the interface, enzyme molecules is lubricated and dispersed well by water, and synchronously the lid is kept open by organic phase. So substrates are allowed to access the active site and then the excellent interfacial activity of lipases is observed at the water/oil interface [16]. This inspired researchers with great interests in simulation of the interfacial activation by immobilizing lipases on carriers [17], encapsulating them in gel [5] and cross-linking enzyme molecules [18], etc. Furthermore, if the immobilization of enzymes can create an environment, as the reaction system in which synthesis can effectively proceed at room temperature [19], or even an environment, which makes it possible to avoid excessively considering the effect of temperature and shaking condition on enzymatic reaction, then the immobilized lipases will be exceptionally favored in green synthesis for that energy consumption may be almost neglected in a sense.

Based on the understanding mentioned above, it is crucial for enzyme immobilization to select an ideal material as carrier, which can replace water to optimize and disperse lipases in organic phases. In chemical composition, it is conceived that the carrier material ought to be inert macromolecules having numerous hydroxyl groups and large specific surface, especially natural product nicely biocompatible with enzyme proteins. These properties happen to be owned by cotton fiber for that the natural product has a fluffy fibrous structure composed of a large amount of glucose linked by glycoside bonds and then has a large specific surface in which there are a lot of hydroxyl groups [20]. Moreover, considering the application of immobilized lipase in anhydrous organic phase, the enzyme immobilization is imagined to be carried out by the physical adsorption method for convenient operation [12]. In this paper, the commercially available Pseudomonas cepacia lipase (PCL) [21], is employed and immobilized on cotton fibers in a column glass bottle by physical adsorption to form a simple bioreactor together with the bottle (Figure 1a), and used to catalyze synthesis of fruit odor hexyl acetate by transesterification of hexanol with vinyl acetate. As a result, an enhanced transesterification catalyzed in the bioreactor is observed, even at room temperature and in static state.

\section{Materials and methods}

\subsection{Materials and apparatus}

Native PCL (33 U/mg) was from Amano Enzyme Inc., Nagoya, Japan, and used without further purification. Hexanol, vinyl acetate and other organic solvents were analytical grade, and these reagents and medical absorbent cotton were bought from Tianjin Baiaotai Technology Development Co., Ltd., China. Lewatit DVB (LDVB, Bayer, Cologne, Germany), Purolite DVB (PDVB, Purolite, Wales, UK) and Purolite C-18 (PC-18, Purolite) were three hydrophobic macroporous adsorption resin micropheres used as enzyme immobilization carriers for comparison with the cotton.

The water content $(\sim 2 \%)$ of lipases was measured using a Karl Fischer coulometer (Metrohm KF-756, Switzerland). Immobilization and reaction were carried out in a thermostationary shaking incubator (HZQ-X, Harbin, China). Immobilizing PCL on cotton fiber and drying cotton fiber were conducted in an electric thermostationary drying oven (DHG-9240A, Shanghai, China). Static enzyme-catalyzed reactions were processed in a thermostationary incubator (BSC-150, Shanghai, China). Reaction kinetics were monitored by gas chromatograph (GC, Echrom A90, Shanghai, China) equipped with a hydrogen flame ionization detector and a capillary column (SE-30 $30 \mathrm{~m} \times 0.32 \mathrm{~mm} \times 0.33 \mu \mathrm{m})$. Kinetic curves of reactions were fitted by Origin 9.0.

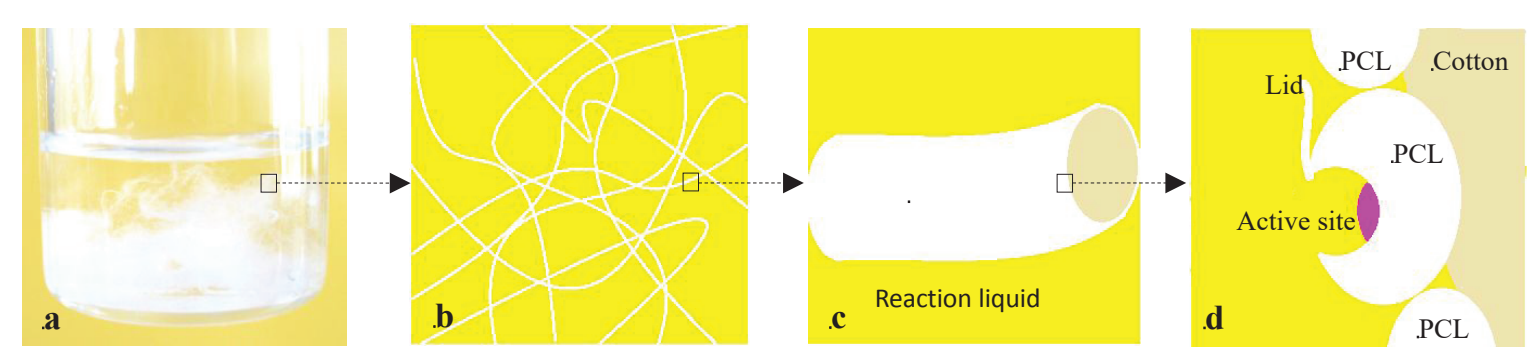

Figure 1: The partial picture of cotton-PCL bioreactor (a) and the structural sketches of locally enlarged cotton filaments (b), fiber segment (c) and cotton-PCL (d). 


\subsection{Pretreatment of enzyme immobilization carriers}

Medical absorbent cotton was pretreated by taking $20 \mathrm{~g}$ cotton fiber soaked in $200 \mathrm{~mL}$ ethanol for $24 \mathrm{~h}$ and washed twice with equal volume of ethanol, dried at $60^{\circ} \mathrm{C}$ for $2 \mathrm{~h}$, and sealed in the beaker with sealing film for application as carrier of enzyme immobilization. LDVB, PDVB and PC-18 were soaked in two-fold volume of ethanol for $24 \mathrm{~h}$ and filtrated. In this method. Again they were treated so twice and dried at $60^{\circ} \mathrm{C}$ for $2 \mathrm{~h}$, and sealed in three beaker with sealing film for application as carriers of enzyme immobilization, respectively.

\subsection{Immobilization of PCL on four carriers and therefore catalysis}

$400 \mu \mathrm{L}$ solution of $0.25 \%$ PCL solution was adsorbed by $10 \mathrm{mg}$ pretreated cotton in a $10 \mathrm{~mL}$ column glass bottle, and then the bottle with mouth open was kept at $37^{\circ} \mathrm{C}$ and $160 \mathrm{rpm}$ for over $14 \mathrm{~h}$ to obtain the cotton-immobilized PCL in a ratio of $10 \mathrm{mg}: 1 \mathrm{mg}$, or called cotton-PCL for short. Incidentally, the cotton-PCL in the bottle should be carefully pulled into fluffy sate by tweezers before use, and the fluffy cotton-PCL, together with the bottle, forms a simple bioreactor.

In the above method, if the $10 \mathrm{mg}$ of pretreated cotton was replaced by $500 \mathrm{mg}$ of resin, then PCL could be immobilized on LDVB, PDVB and PC-18 to obtained three resin-immobilized enzymes LDVB-PCL, PDVB-PCL and PC-18-PCL all in a ratio $500 \mathrm{mg}: 1 \mathrm{mg}$.

In the $10 \mathrm{~mL}$ column glass bottle with cotton-PCL, LDVB-PCL, PDVB-PCL or PC-18-PCL, hexanol and vinyl acetate were added in a ratio of $1.5 \mathrm{~mL}: 1.5 \mathrm{~mL}$, i.e. $12 \mathrm{mmol}: 16 \mathrm{mmol}$, and then covered with lid and sealed with sealing film for catalytic transesterification at $37^{\circ} \mathrm{C}$ and $160 \mathrm{rpm}$. The temperature and the rotation rate were conditions often adopted in enzymatic reactions $[4,5]$. The kinetics of transesterificaton reaction systems catalyzed by the four immobilized lipases were periodically analyzed by GC.

\subsection{Immobilization of PCL on cotton fiber and therefore catalysis}

$10 \mathrm{mg}$ native PCL and $200 \mu \mathrm{L}$ water were added in a $10 \mathrm{~mL}$ column glass bottle in order. Shaking gently caused PCL dissolved in water, and then a certain mass of pretreated cotton fiber was put into the bottle to absorb enzyme solution adequately. The bottle with mouth open was kept in an incubator at $37^{\circ} \mathrm{C}$ and $160 \mathrm{rpm}$ over $7 \mathrm{~h}$ to get cotton-PCL in which cotton fiber mass was different. On the other hand, the above performance was repeated by using $10 \mathrm{mg}$ cotton fiber and mass-different PCL to prepare cotton-PCL in which PCL mass was different.

In the bottle with cotton-PCL in different mass ratio, hexanol and vinyl acetate were added in a ratio of $1.5 \mathrm{~mL}: 1.5 \mathrm{~mL}$, and then covered with lid and sealed with sealing film for catalytic transesterification at $37^{\circ} \mathrm{C}$ and $160 \mathrm{rpm}$ for $12 \mathrm{~h}$. Each performance was repeated three times and the molar conversion of every reaction system was analyzed by GC.

\subsection{Transesterifications catalyzed by cotton-PCL and native PCL}

In a $10 \mathrm{~mL}$ column glass bottle, the cotton-PCL with $10 \mathrm{mg}$ cotton and $10 \mathrm{mg}$ PCL was prepared by the aforesaid way and carefully pulled into fluffy sate by tweezers to form the bioreactor together with the bottle. In the bioreactor, hexanol and vinyl acetate were added in a ratio of $1.5 \mathrm{~mL}: 1.5 \mathrm{~mL}$, and covered with lid and sealed with sealing film for catalytic transesterification at $37^{\circ} \mathrm{C}$ and $160 \mathrm{rpm}$. At the same time, $10 \mathrm{mg}$ native PCL powder was added in anther $10 \mathrm{~mL}$ column glass bottle with $1.5 \mathrm{~mL}$ hexanol and $1.5 \mathrm{~mL}$ vinyl acetate for catalytic transesterification under same reaction conditions after the bottle was covered with lid and sealed with sealing film. The kinetics of two reaction systems were periodically analyzed by GC.

In addition, the two control reaction systems were arranged for implementation at room temperature $25^{\circ} \mathrm{C}$ and in static state $0 \mathrm{rpm}$, or at $4^{\circ} \mathrm{C}$ and $0 \mathrm{rpm}$. Also the kinetics of reaction systems were periodically analyzed by GC.

\subsection{GC analytical conditions}

$2 \mathrm{~mL}$ reaction liquid was taken from reaction system regularly, diluted by $2 \mathrm{~mL}$ hexane, filtrated with $0.22 \mu \mathrm{m}$ organic filtration membrane, and analyzed by GC. Nitrogen was taken as carrier gas at a column flow of $1.7 \mathrm{~mL} / \mathrm{min}$ and in a split ratio of 1:1. The column program was set as $90^{\circ} \mathrm{C}$ for $1 \mathrm{~min}, 15^{\circ} \mathrm{C} / \mathrm{min}$, and $130^{\circ} \mathrm{C}$ for $1.5 \mathrm{~min}$. Injector and detector were set at $280^{\circ} \mathrm{C}$ and $300^{\circ} \mathrm{C}$, respectively. The retention time was $2.47 \mathrm{~min}$ for hexanol and $3.48 \mathrm{~min}$ for product hexyl acetate. 


\section{Results and discussion}

\subsection{Primarily exploration on catalysis of cotton-PCL}

According to the interfacial activation mechanism of lipases [9-11], it is known that water is essential for optimization and stabilization of lipases surrounded by organic solvents. If there is a solid material that can replace water and does not participate in the enzymatic reaction, then it can be employed as desired carrier to prepare immobilized lipases to effectively catalyze the transesterification for synthesis of ester compounds in organic phases. Based on the conception, cotton fiber seems to be a desired carrier for enzyme immobilization because the material is consisted of fluffy fibers in which there are a large hydroxyl groups, like water, naturally having ability to stabilize enzyme protein. To test the idea, ethanol-pretreated cotton fiber was employed as a carrier to prepare cotton-PCL by physical absorption and compare with three popular hydrophobic resin microspheres LDVB, PDVB and PC-18 commonly employed as carriers to immobilize lipases [22]. Referring the loading ratio of lipase to carriers seen in the literatures [23,24] and considering the $3 \mathrm{~mL}$ of reaction system $(1.5 \mathrm{~mL}$ hexanol and $1.5 \mathrm{~mL}$ vinyl acetate) adopted in this paper, the loading ratios of PCL to resins and cotton fiber were set as $1 \mathrm{mg}: 500 \mathrm{mg}$ and $1 \mathrm{mg}$ : $10 \mathrm{mg}$, respectively. Here, $500 \mathrm{mg}$ resin particles can dispersed well in $3 \mathrm{~mL}$ of reaction liquid under $160 \mathrm{rpm}$, and $10 \mathrm{mg}$ fluffy cotton fibers are also better filled with the reaction system. From the kinetic curves of them in catalyzing reaction of hexanol with vinyl acetate at $37^{\circ} \mathrm{C}$ and $160 \mathrm{rpm}$ (Figure 2), it is found that cottonPCL behaves transesterification obviously better than

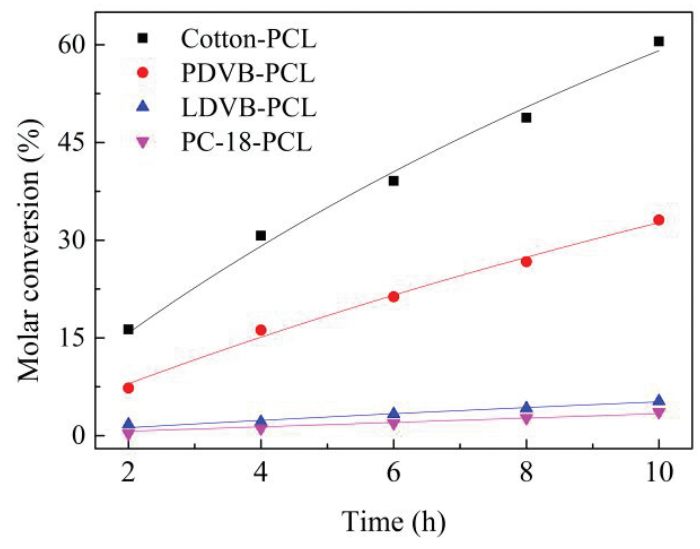

Figure 2: Kinetics of cotton-PCL, LDVB-PCL, PDVB-PCL and PC-18$P C L$ in which $P C L$ is $1 \mathrm{mg}$.
LDVB, PDVB and PC-18. That is to say that cotton fiber is available material as carrier for PCL immobilization.

\subsection{Dosage of cotton fiber and PCL}

Preliminary trials showed that ethanol-pretreated cotton fiber played a positive role as an inert carrier to prepare immobilized PCL and improve nonaqueous catalysis of PCL. Further the dosage of cotton fiber in cotton-PCL should be determined for that obviously the dosage of carrier has effect on dispersion of enzyme molecules so as to change the ability of them to transform substrates [24]. For knowing the appropriate dosage of cotton fiber, $10 \mathrm{mg}$ of PCL was immobilized on mass-different cotton fibers by physical adsorption and used to catalyze transesterification of hexanol with vinyl acetate at $37^{\circ} \mathrm{C}$ and $160 \mathrm{rpm}$, which were reaction conditions usually preferred by PCL $[25,26]$. From the molar conversion (c) of reaction catalyzed by cotton-PCL for $12 \mathrm{~h}$, although the results fluctuate due to operational errors, it can be seen that cotton-PCL was endowed with relatively high activity when cotton fiber is in the range from 7 to $11 \mathrm{mg}$ (Figure 3). The reason is inferred that cotton fibers less than $7 \mathrm{mg}$ can not provide enough specific surface area to fully disperse PCL protein molecules. On the contrary, cotton fibers larger than $11 \mathrm{mg}$ have smaller interstitial volume, which limits the diffusion of reaction solution in the interstitial space of fibers immobilized with PCL. Therefore, in order to disperse the enzyme protein as much as possible without affecting the diffusion of reaction solution, the mass of cotton fiber as carrier was fixed at $10 \mathrm{mg}$ for the preparation of cotton-PCL based on the experimental results (Figure 3).

Similarly, the proper mass of PCL was determined by immobilizing mass-different PCL on $10 \mathrm{mg}$ of cotton fiber and catalyzing reaction of hexanol with vinyl acetate. The

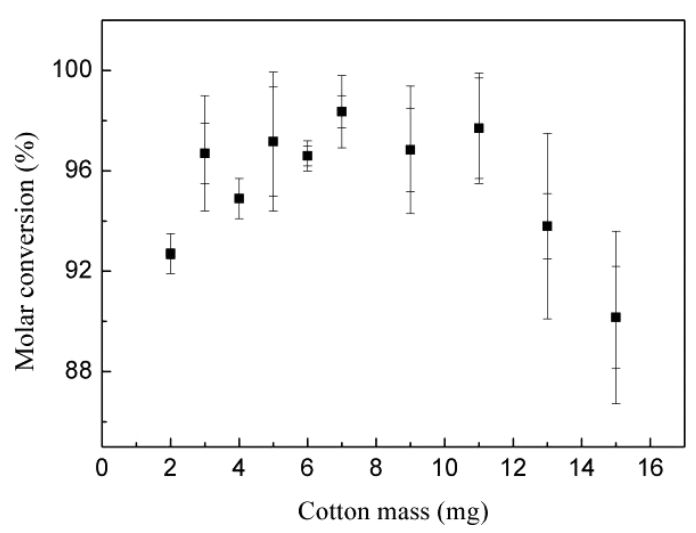

Figure 3: Molar conversion of hexanol reacting with vinyl acetate catalyzed by cotton-PCLs (10 mg PCL and 2-15 mg cotton). 
results show that the conversion of reaction catalyzed by cotton-PCL for $12 \mathrm{~h}$ at $37^{\circ} \mathrm{C}$ and $160 \mathrm{rpm}$, increases with dosage of PCL in cotton-PCL but increases slowly when PCL exceeds $10 \mathrm{mg}$ (Figure 4). So the mass of PCL is designated as $10 \mathrm{mg}$ in preparation of cotton-PCL, to carry out related researches as follow. In a mass ratio of $10 \mathrm{mg}: 10 \mathrm{mg}$, the cotton filaments immobilized with PCL still had fine flexibility and no PCL fragments fell away from fibers when they were stretched and bent by tweezers. In fact, the fluffy cotton-PCL, together with the column glass bottle in which enzyme immobilization was carried out, formed a simple cotton-PCL bioreactor convenient for the transesterification (Figure 1a).

\subsection{Comparing activity of cotton-PCL with native $\mathrm{PCL}$}

The mentioned bioreactor with cotton-PCL was prepared by immobilizing PCL on cotton fibers in a mass ratio of $10 \mathrm{mg}$ : $10 \mathrm{mg}$ via physical adsorption and pulled into fluffy state. In catalyzing reaction of hexanol with vinyl acetate $(1.5 \mathrm{~mL}: 1.5 \mathrm{~mL})$ at $37^{\circ} \mathrm{C}$ and $160 \mathrm{rpm}$ (Figure 5$)$, the molar conversions showed that the bioreactor behaved significant increase in catalytic activity relative to the equal mass of native PCL in column glass bottle. Before $2 \mathrm{~h}$, cotton-PCL was 3 folds more than native PCL in the ability to transform substrate, and at this time cottonPCL transformed about half of hexanol and native PCL only transformed less than $1 / 6$ of hexanol. From then on, until two days later, cotton-PCL was about twice as active as native PCL in catalytic activity throughout $48 \mathrm{~h}$ of reaction. This means that the cotton fibers not only activates PCL greatly but also stabilizes it well, which is believed to be due to the adsorption and stabilization of

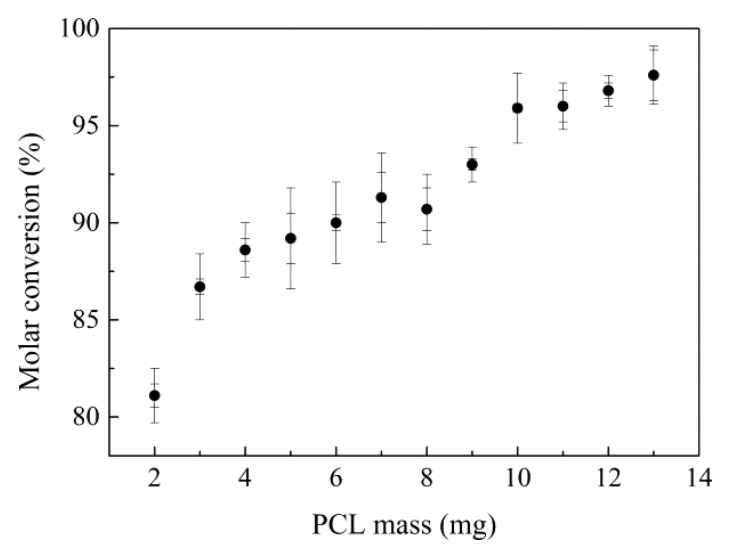

Figure 4: Molar conversion of hexanol reacting with vinyl acetate catalyzed by cotton-PCLs (10 mg cotton and 2-13 mg PCL).
PCL molecules by a abundant hydroxyl groups distributed in cotton filaments.

\subsection{Stability of cotton-PCL}

To further test the stability of cotton-PCL in organic phase, it was recycled in transesterification of hexanol with vinyl acetate for $6 \mathrm{~h}$ once. As far as the conversions of six recycled catalytic reactions, there is little reduction but somewhere fluctuations as cotton-PCL is used more often (Figure 6). This less reduction of cotton-PCL in activity was ever what expected by researchers engaged in lipases immobilized on carriers such as nanoparticles [27], porous microspheres [28] and mesoporous material [29], etc. As control, native PCL exhibited obviously gradual attenuation in the ability to transform substrate during the course of reuse (Figure 6). To refer literature [30], the half life $t_{1 / 2}$ of cotton-PCL in activity was estimated by the Eq. 1 and 2.

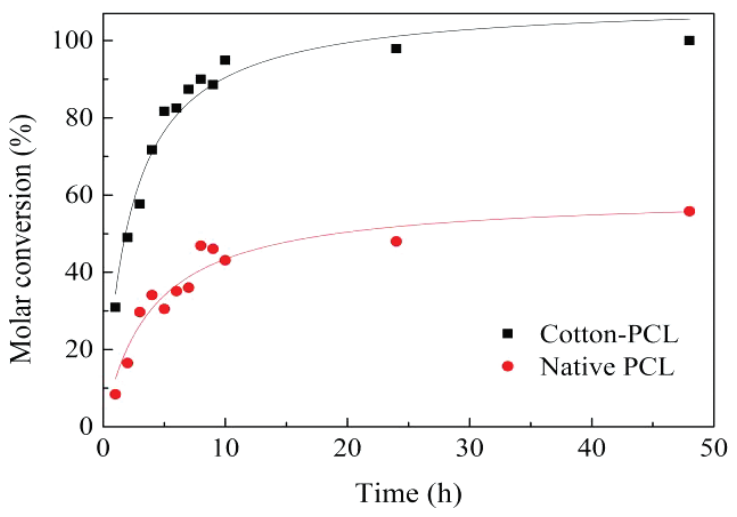

Figure 5: Kinetics of cotton-PCL and native $P C L$ in catalyzing reaction of hexanol with vinyl acetate at $37^{\circ} \mathrm{C}$ and $160 \mathrm{rpm}$.

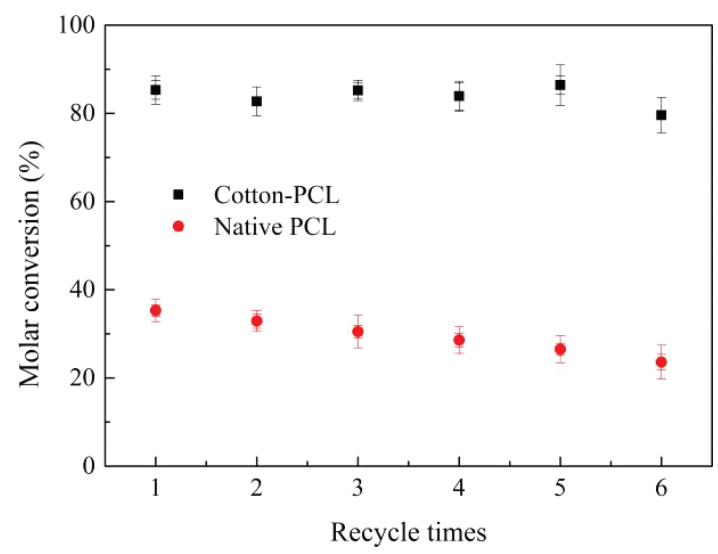

Figure 6: Conversions of transesterifications catalyzed by cotton$\mathrm{PCL}$ and native $\mathrm{PCL}$ for six times once six hours at $37^{\circ} \mathrm{C}$. 


$$
\begin{gathered}
\ln A=\ln \left(A_{0}\right)-k_{\mathrm{d}} t \\
t_{1 / 2}=\frac{\ln (0.5)}{-k_{\mathrm{d}}}
\end{gathered}
$$

where $A_{0}$ is the initial activity, $A$ is the residual activity after time $t$, and $k_{\mathrm{d}}$ is the first-order deactivation rate coefficient related to $A_{0}, A$ and $t$. For organic system [31], $A_{0}$ can be represented by the first molar conversion $85.3 \%$, namely which is taken as $A$ value at $0 \mathrm{~h}$. And the conversions of post five times are regarded as five $A$ values after each subsequent $6 \mathrm{~h}$. The coordinate points $(t, \ln A)$ were plotted and linearly fitted by Origin 9.0 and the generated slope value is the $-k_{\mathrm{d}}$ value in Eq. 1 and 2, which is -0.00109 for cotton-PCL and 0.01298 for native PCL (Figure 7). From the Eq. 2, the $t_{1 / 2}$ values of cotton-PCL and native PCL are $636 \mathrm{~h}$ and $53 \mathrm{~h}$, respectively. Though the $t_{1 / 2}$ value of cottonPCL is extraordinarily long and it seems that cotton-PCL is very stable in organic phase, the linearity is not very good, that is to say, the experimental results have obvious big errors, which should be originated from the experimental operation.

Nevertheless, in general, the higher non-aqueous activity of cotton-PCL is very obvious, and the nonaqueous stability of cotton-PCL is believed to originate from the composition and structure of cotton fiber [20]. Cotton fibers have abundant hydroxyl groups that, like water, benefit stabilization of enzyme proteins [32]. Also the naturally fibrous flexibility of cotton fibers might be beneficial to the enzyme conformation changes usually demanded in catalysis [33]. Besides, the numerous slender filaments of cotton fibers present cotton-PCL with large specific surface and interval volume (Figure $1 b)$, which help contacts between enzyme molecules and substrates.

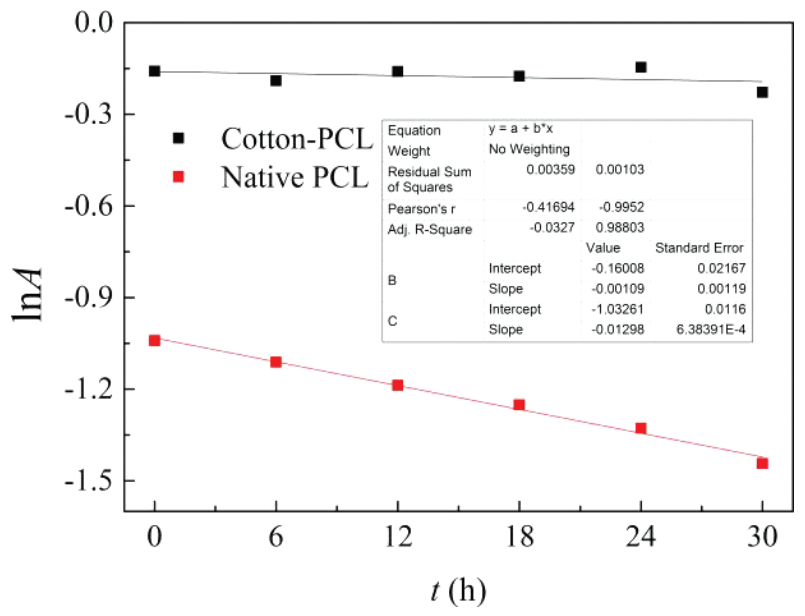

Figure 7: Linear fitting of coordinate points by taking conversion as $A$ value and time as $t$ value, based on the Figure 6 .

\subsection{Catalysis of cotton-PCL bioreactor at room temperature and in static state}

What's more interesting is that the cotton-PCL bioreactor still has high catalytic activity at room temperature $25^{\circ} \mathrm{C}$, or even at $4^{\circ} \mathrm{C}$, and in static state. If the bioreactor with reaction solution remained stationary at $25^{\circ} \mathrm{C}$ for $8 \mathrm{~h}$, the reaction conversion could achieve at $82.8 \%$ (Figure 8), being only $7.2 \%$ lower than that under shaking and warmer conditions, i.e. at $160 \mathrm{rpm}$ and $37^{\circ} \mathrm{C}$ (Figure 5). Let the bioreactor stand at $25^{\circ} \mathrm{C}$ for $24 \mathrm{~h}$, the reaction was almost over, and after $48 \mathrm{~h}$, the substrate molecules were transformed completely and the conversion achieved at $100 \%$ (Figure 8 ). Even at $4^{\circ} \mathrm{C}$, the static bioreactor still behaved excellent activity relative to native PCL, and gave a conversion almost equal to that at $25^{\circ} \mathrm{C}$ after $48 \mathrm{~h}$ (Figure 8). All these show that the cotton-PCL bioreactor can work well at room or lower temperature, and in static state. Namely, an environment suitable for transesterification of hexanol with acetate is presented in the bioreactor in which the reaction temperature and shaking condition need little to be cared. Comparing with high temperature [34], ultrasound [35] and supercritical condition [36], the bioreactor is low energy consumption device and more suitable for catalytic synthesis of hexyl acetate. The room temperature-static catalysis was seldom found in some immobilized enzymes even though they also had large specific surface area and interval volume, e.g. lipases immobilized on carriers with matrix structure [37] and lipases cross-linked [38]. This might be that cotton fibers rely on its flexibility to make specific surface and interval volume of cottonPCL more effective in promoting enzyme to effectively contact with reaction solution (Figures $1 \mathrm{~b}$ and $1 \mathrm{c}$ ).

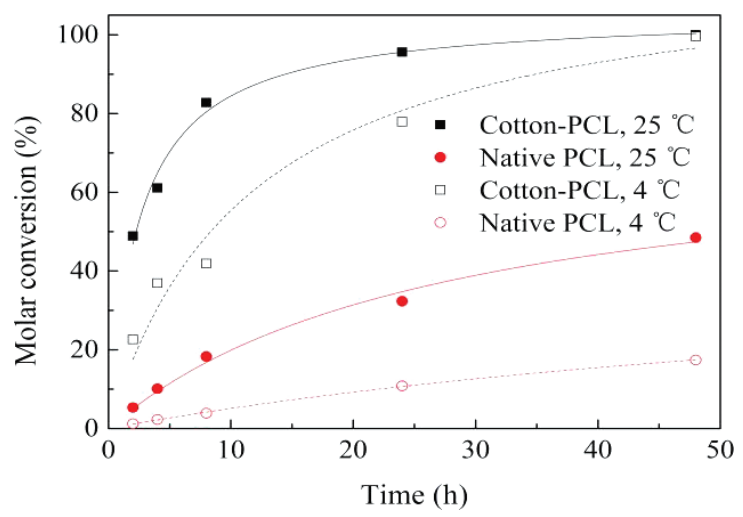

Figure 8: Conversions of transesterifications catalyzed by cotton$\mathrm{PCL}$ and native $\mathrm{PCL}$ at 25 or $4^{\circ} \mathrm{C}$ and in static state. 


\section{Conclusions}

It is shown that cotton fiber is a desired material, in place of water, to stabilize enzyme conformation and can be used as carrier to prepare immobilized enzyme cottonPCL. The cotton-PCL can be prepared by using cotton fiber to adsorb PCL solution in a column glass bottle and then setting the bottle with mouth open at $37^{\circ} \mathrm{C}$ and $160 \mathrm{rpm}$ for more than $7 \mathrm{~h}$. The cotton-PCL, together with the bottle, forms a simple bioreactor in which cotton fibers, relying on numerous hydroxyl groups, fluffy structure, large specific surface, interval volume and natural flexibility, endow cotton-PCL with high activity and excellent stability in catalyzing transesterification of hexanol with vinyl acetate. In terms of molar conversion, cotton-PCL is about twice as much as native PCL in activity throughout $48 \mathrm{~h}$ of reaction process. Recycling cotton-PCL in the transesterification shows that the half life $t_{1 / 2}$ of catalytic activity continues up to $636 \mathrm{~h}$. In particular, the cottonPCL still displays catalysis well at $25^{\circ} \mathrm{C}$ and in static state, due to its fluffy structure and abundant hydroxyl groups. All these indicate that cotton fiber as carrier to prepare immobilized lipases has significantly potential application in nonaqueous enzymatic industry. However, the detail work still needs to be carried out in the future for instance further testing the half life of cotton-PCL via longer time use in organic phase as well as use in other organic phases.

Acknowledgments: This work was funded by the Key Project of Tianjin Natural Science Foundation (18JCZDJC97800), the Open Fund of Tianjin Key Lab of Aquatic Ecology and Aquaculture (TJAE201802), the Modern Aqua-ecology and Health Aquaculture Innovation Team of Tianjin (TD13-5089), the Tianjin Aquatic Industry Technical System-Water Quality Control Position (ITTFRS2018015), the National innovation and Entrepreneurship Program for undergraduates (201910061013), and the Open Fund of Key Laboratory of Storage of Agricultural Products, Ministry of Agriculture and Rural Affairs (KF2018005).

\section{References}

[1] Itoh T., Hanefeld U., Enzyme catalysis in organic synthesis. Green Chem., 2017, 19(2), 331-332.

[2] Salihu A., Alam M.Z., Solvent tolerant lipases: A review. Process Biochem., 2015, 50, 86-96.

[3] Molinagutiérrez M., Hakalin N.L., Rodríguezsanchez L., Prieto A., Martínez M.J., Green synthesis of $\beta$-sitostanol esters catalyzed by the versatile lipase/sterol esterase from ophiostoma piceae. Food Chem., 2017, 221, 1458-1465.

[4] Cai X., Wang W., Lin L., He D., Shen Y., Wei W., et al., Cinnamyl esters synthesis by lipase-catalyzed transesterification in a non-aqueous system. Catal. Lett., 2017, 147(4), 946-952.

[5] de Araújo M.E., Franco Y.E., Messias M.C., Longato G.B., Pamphile J.A., et al., Biocatalytic synthesis of flavonoid esters by lipases and their biological benefits. Planta Med., 2017, 83(01/02), 7-22.

[6] Kumar A., Dhar K., Kanwar S.S., Kumar A.P., Lipase catalysis in organic solvents: advantages and applications. Biol. Proced. Online, 2016, 18, 1-11

[7] Cao Y., Zhuang Y., Yao C., Wu B., He B., Purification and characterization of an organic solvent-stable lipase from Pseudomonas stutzeri LC2-8 and its application for efficient resolution of (R, S)-1-phenylethanol. Biochem. Eng. J., 2012, 64, 55-60.

[8] Xie Y., An J., Yang G., Wu G., Zhang Y., Cui L., et al., Enhanced enzyme kinetic stability by increasing rigidity within the active site. J. Biol. Chem., 2014, 289, 7994-8006.

[9] Cui C., Guan N., Xing C., Chen B., Tan T., Immobilization of Yarrowia lipolytica lipase Ylip2 for the biocatalytic synthesis of phytosterol ester in a water activity controlled reactor. Colloid Surface. B, 2016, 146, 490-497.

[10] Quilles J.C.J, Brito R.R., Borges J.P., Aragon C.C., FernandezLorente G., Bocchini-Martins D.A., et al., Modulation of the activity and selectivity of the immobilized lipases by surfactants and solvents. Biochem. Eng. J., 2015, 93, 274-280.

[11] Sóti V.P.L., Weiser D., Vigh T., Nagy Z.K., Poppe L., Marosi G., Electrospun polylactic acid and polyvinyl alcohol fibers as efficient and stable nanomaterials for immobilization of lipases. Bioproc. Biosyst. Eng., 2016, 39, 449-459.

[12] Zhao X., Qi F., Yuan C., Du W., Liu D.H., Lipase-catalyzed process for biodiesel production: Enzyme immobilization, process simulation and optimization. Renew. Sustain. Energ. Rev., 2015, 44, 182-197.

[13] Stergiou P.Y., Foukis A., Filippou M., Koukouritaki M., Parapouli M., Theodorou L.G., et al., Advances in lipasecatalyzed esterification reactions. Biotechnol. Adv., 2013, 31, 1846-1859.

[14] Herbst D., Peper S., Niemeyer B., Enzyme catalysis in organic solvents: influence of water content, solvent composition and temperature on Candida rugosa lipase catalyzed transesterification. J. Biotechnol., 2012, 162, 398-403.

[15] Su F., Peng C., Li G.L., Xu L., Yan Y.J., Biodiesel production from woody oil catalyzed by Candida rugosa lipase in ionic liquid. Renew. Energ., 2016, 90, 329-335.

[16] Brzozowski A.M., Derewenda U., Derewenda Z.S., Dodson G.G., Lawson D.M., Turkenburg J.P., et al., A model for interfacial activation in lipases from the structure of a fungal lipaseinhibitor complex. Nature, 1991, 351, 491-494. 
[17] Todero L.M., Bassi J.J., Lage F.A., Corradini M.C., Barboza J.C., Hirata D.B., et al., Enzymatic synthesis of isoamyl butyrate catalyzed by immobilized lipase on poly-methacrylate particles: optimization, reusability and mass transfer studies. Bioproc. Biosyst. Eng., 2015, 38, 1601-1613.

[18] Mehta J., Bhardwaj N., Bhardwaj S.K., Kim K.H., Deep A., Recent advances in enzyme immobilization techniques: metal-organic frameworks as novel substrates. Coordin. Chem. Rev., 2016, 322, 30-40.

[19] Zavabeti A., Ou J.Z., Carey B.J., Syed N., Orrell-Trigg R., Mayes E.L.H., et al., A liquid metal reaction environment for the roomtemperature synthesis of atomically thin metal oxides. Science, 2017, 358(6361), 332-335.

[20] Yu Y., Yuan J., Wang Q., Fan X., Wang P., Cui L., A study of surface morphology and structure of cotton fibres with soluble immobilized-cellulase treatment. Fiber. Polym., 2014, 15, 16091615.

[21] Gotor-Fernández V., Vicente G., Use of Lipases in Organic Synthesis. In: Polaina J., MacCabe A.P. (Eds), Industrial Enzymes. Springer, Dordrecht, 2007.

[22] Corović M., Mihailović M., Banjanac K., Carević M., Milivojević A., Milosavić N., et al., Immobilization of Candida antarctica lipase B onto Purolite ${ }^{\circledR}$ MN102 and its application in solventfree and organic media esterification. Bioproc. Biosyst. Eng., 2017, 40, 23-34.

[23] Palomo J.M., Muñoz G., Fernández-Lorente G., Mateo C., Fernández-Lafuente R., Guisán J.M., Interfacial adsorption of lipases on very hydrophobic support (octadecyl-Sepabeads): immobilization, hyperactivation and stabilization of the open form of lipases. J. Mol. Catal. B-Enzym., 2002, 19-20 and 279-286.

[24] Hernandez K., Fernandez-Lafuente R., Lipase B from Candida antarctica immobilized on octadecyl Sepabeads: a very stable biocatalyst in the presence of hydrogen per-oxide. Process Biochem., 2011, 46, 873-878.

[25] Badgujar K.C., Pai P.A., Bhanage B.M., Enhanced biocatalytic activity of immobilized Pseudomonas cepacia lipase under sonicated condition. Bioproc. Biosyst. Eng., 2016, 39, 211-221.

[26] Chen G.C., Kuan I.C., Hong J.R, Tsai B.H., Lee S.L., Yu C.Y., Activity enhancement and stabilization of lipase from Pseudomonas cepacia in polyallylamine-mediated biomimetic silica. Biotechnol. Lett., 2011, 33, 525-529.
[27] Singh A.K., Mukhopadhyay M., Immobilization of Candida antarctica lipase onto cellulose acetate-coated $\mathrm{Fe}_{2} \mathrm{O}_{3}$ nanoparticles for glycerolysis of olive oil. Korean J. Chem. Eng., 2014, 31, 1225-1232.

[28] Tai Y., Wang L., Gao J., Tao W., Huo J., Yang L., Synthesis of core/ shell magnetic porous microspheres for lipase immobilization. J. Inorg. Organomet. P., 2012, 22, 213-222.

[29] Jiang Y., Zheng P., Zhou L., Konga W., Gaoa J., Wanga J., et al., Immobilization of lipase in hierarchically ordered macroporous/ mesoporous silica with improved catalytic performance. J. Mol. Catal. B-Enzym., 2016, 130, 96-103.

[30] Gururaj P., Ramalingam S., Devi G.N., Gautam P., Process optimization for production and purification of a thermostable, organic solvent tolerant lipase from Acinetobacter sp. AU07. Braz. J. Microbiol., 2016, 47, 647-657.

[31] Xun E., Lv X., Kang W., Wang J., Zhang H., Wang L., et al., Immobilization of Pseudomonas fluorescens lipase onto magnetic nanoparticles for resolution of 2-octanol. Appl. Biochem. Biotech., 2012, 168, 697-707.

[32] Adlercreutz P., Immobilisation and application of lipases in organic media. Chem. Soc. Rev., 2013, 42, 6406-6436.

[33] Dachuri V., Boyineni J., Choi S., Chung H.S., Jang S.H., Lee C.W., Organic solvent-tolerant, cold-adapted lipases PML and LipS exhibit increased conformational flexibility in polar organic solvents. J. Mol. Catal. B-Enzym., 2016, 131, 73-78.

[34] Yang Z., Pan Y., Mei Z., Zhanga W., Preparation of mesoporous $\mathrm{MnO}_{2} / \mathrm{C}$ catalyst for $\mathrm{n}$-hexyl acetate synthesis. Appl. Surf. Sci., 2012, 258, 4756-4763.

[35] Deshmukh A.R., Rathod V.K., Intensification of enzyme catalysed synthesis of hexyl acetate using sonication. Green Process. Synth., 2017, 6, 55-62.

[36] Yu Z.R., Chang S.W., Wang H.Y., Shieh C.J., Study on synthesis parameters of lipase-catalyzed hexyl acetate in supercritical $\mathrm{CO}_{2}$ by response surface methodology. J. Am. Oil. Chem. Soc., 2003, 80, 139-144.

[37] Lee K.W., Min K., Park K., Yoo Y.J., Development of an amphiphilic matrix for immobilization of Candida antartica lipase B for biodiesel production. Biotechnol. Bioproc. E., 2010, 15, 603-607.

[38] Rajan A., Abraham T.E., Studies on crystallization and crosslinking of lipase for biocatalysis. Biotechnol. Bioproc. E., 2008, $31,87-94$ 